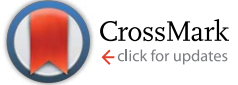

Cite this: J. Mater. Chem. A, 2017, 5, 4583

Received 11th November 2016 Accepted 28th January 2017

DOI: 10.1039/c6ta09751k

rsc.li/materials-a

\section{Flexible thermally treated 3D PIM-CD molecular sieve membranes exceeding the upper bound line for propylene/propane separation}

\begin{abstract}
Jiangtao Liu, Youchang Xiao and Tai-Shung Chung*
Polymers of intrinsic microporosity (PIM) incorporated with beta-cyclodextrin ( $\beta$-CD) (referred to as PIM$\mathrm{CD}$ ) are prepared via nucleophilic substitution copolymerization and then thermally treated at elevated temperatures from 300 to $600{ }^{\circ} \mathrm{C}$. After the decomposition of thermally labile CD, the spaces originally occupied by $C D$ convert to micro-pores and cross-linking points in the polymer matrix. The thermally induced three-dimensional (3D) cross-linking network not only possesses ultra-fine micro-pores and interconnected microvoids but also shows a superior molecular sieve ability for propylene/propane separation. The $\mathrm{C}_{3} \mathrm{H}_{6} / \mathrm{C}_{3} \mathrm{H}_{8}$ selectivity of the thermally treated membranes increases remarkably, about 3 times compared to that of the original untreated membranes. In particular, the PIM-CD membranes thermally treated at 300 or $400{ }^{\circ} \mathrm{C}$ are flexible, and they have $\mathrm{C}_{3} \mathrm{H}_{6} / \mathrm{C}_{3} \mathrm{H}_{8}$ separation performance exceeding the upper bound line in both pure and mixed gas tests. As observed from the gas sorption isotherms, membranes with a higher content of $C D$ units have a higher gas sorption capacity. Additionally, the diffusivity selectivity of PIM-CD membranes after thermal treatment increases more quickly than that of the PIM membrane and contributes more to the permeability selectivity.
\end{abstract}

\section{Introduction}

Since propylene is the second largest feedstock for the production of commonly used plastics (e.g. polypropylene) and chemicals (e.g. isopropanol, acrylonitrile, and propylene oxide), the separation of propylene from propylene/propane mixtures is one of the most important processes in the petrochemical industry. ${ }^{1}$ The current dominant process for $\mathrm{C}_{3} \mathrm{H}_{6}$ and $\mathrm{C}_{3} \mathrm{H}_{8}$ separation, cryogenic distillation, is extremely energy intensive due to their close boiling points, high volatility and condensability characteristics. ${ }^{2-5}$ Membrane technology, ${ }^{3-7}$ which possesses advantages of low energy consumption, easy operation and maintenance, small footprint and operational cost, and environmental friendliness, is one of the potential strategy to debottleneck the traditional separation process.

Until now, many kinds of membrane materials have been tried for propylene/propane separation, such as (1) pure polymeric membranes, (2) metal ion doped membranes, (3) mixed matrix membranes, and (4) carbon molecular sieve (CMS) membranes. Merits coexist with drawbacks in each kind of membrane material. Polymeric membranes are relatively inexpensive and easy to scale up, but their $\mathrm{C}_{3} \mathrm{H}_{6} / \mathrm{C}_{3} \mathrm{H}_{8}$ separation performance often suffers from the trade-off relationship between permeability and selectivity. ${ }^{\mathbf{1 , 3 - 5 , 7 - 1 5}}$ For example, polyimide membranes prepared from Matrimid ${ }^{\circledR} 5218$ have a high

Department of Chemical and Biomolecular Engineering, National University of Singapore, Singapore 117585. E-mail: chencts@nus.edu.sg; Fax: +65-67791936
$\mathrm{C}_{3} \mathrm{H}_{6} / \mathrm{C}_{3} \mathrm{H}_{8}$ selectivity of 10 but an extremely low $\mathrm{C}_{3} \mathrm{H}_{6}$ permeability of 0.1 barrer. $^{3}$ As a result, it's a challenge to design polymeric membranes with both high permeability and good selectivity simultaneously.

Metal ion doped membranes often possess good $\mathrm{C}_{3} \mathrm{H}_{6} / \mathrm{C}_{3} \mathrm{H}_{8}$ separation performance due to specific interactions between the olefin's hybrid molecular orbitals and the metal's atomic orbitals. ${ }^{5,16-21}$ However, metal ion doped membranes also face the inherit problems of short life time and carrier poisoning induced by trace amounts of methyl acetylene and sulfur impurities in the $\mathrm{C}_{3} \mathrm{H}_{6} / \mathrm{C}_{3} \mathrm{H}_{8}$ feed mixture. ${ }^{22}$ Mixed matrix membranes consisting of MOF or ZIF nanoparticles in polymer matrices are promising materials because they combine the merits of both polymer and molecular sieving characteristics. ${ }^{\text {923-27 }}$ However, poor compatibility between nanoparticles and polymer matrices often results in particle agglomeration and defective membranes.

Carbon molecular sieve (CMS) membranes have received considerable attention because of their good thermal and chemical stability and superior gas separation performance. ${ }^{3,28-33}$ However, CMS membranes suffer from the drawbacks of brittleness and high energy consumption and costs. Until now, no CMS membranes derived from the PIM precursor are reported for $\mathrm{C}_{3} \mathrm{H}_{6} / \mathrm{C}_{3} \mathrm{H}_{8}$ separation even though some data were available for $\mathrm{C}_{2} \mathrm{H}_{4} / \mathrm{C}_{2} \mathrm{H}_{6}$ separation. ${ }^{34,35}$ Therefore, we aim to explore if we can develop flexible thermally treated PIM membranes for $\mathrm{C}_{3}$ separation with performance exceeding the upper bound of the trade-off relationship. 
Polymers of intrinsic microporosity (PIM) were chosen in this study because they possess extremely high free volume and surface areas. ${ }^{36-40}$ The ladder-type structure and rigidly contorted spiro-carbon sites can prevent polymer chains from becoming densely packed. However, the linear PIM polymer chains interact with each other by relatively weak van der Waals' forces which may easily slide over one another. To enhance inter-chain interactions and improve molecular sieve characteristics, Liu et al. incorporated $\beta$-cyclodextrin ( $\beta$-CD) with a unique 3D hollow bowl structure into PIM chains (referred to as PIM-CD). ${ }^{41}$ The incorporation of a very small amount of $\beta-C D$ into PIM significantly enhanced the gas permeability that surpassed the Robeson upper bound without much compromising the selectivity. The PIM-CD membrane also exhibited a greater resistance to physical aging than the PIM membrane.

Since $\beta-C D$ is a thermally labile molecule containing multiple reactive hydroxyl groups, one may convert the highly permeable PIM-CD precursor to covalently cross-linked polymer networks with significantly improved molecular-sieving properties by thermal annealing. The thermally labile CD units may decompose and create microvoids as well as generate free radicals, which can effectively accelerate the self-cross-linking reaction within the rigidly contorted PIM polymer framework. As a result, the annealed PIM-CD membrane has not only a large free volume for gas transport but also a tighter structure to separate $\mathrm{C}_{3} \mathrm{H}_{6} / \mathrm{C}_{3} \mathrm{H}_{8}$ mixtures. Therefore, various annealing temperatures from 300 to $600{ }^{\circ} \mathrm{C}$ would be used to investigate their effects on the chemical structure and gas separation performance of PIM-CD membranes under both pure gas and mixed gas testing environments. These results may open up new avenues for molecular designing of highly permeable membranes for propylene/propane separation.

\section{Experimental}

\subsection{Materials}

$\beta$-Cyclodextrin ( $\beta$-CD) was purchased from Cyclolab Ltd and dried overnight at $100{ }^{\circ} \mathrm{C}$ under vacuum prior to use. The molecular weight of the dehydrated $\beta$-CD (formula: $\left.\left(\mathrm{C}_{6} \mathrm{H}_{10} \mathrm{O}_{5}\right)_{7}\right)$ is 1134. The outer diameter of the larger opening of the $\beta$-CD toroid is $15.3 \AA$, the side rim depth is $7.8 \AA$ and the inner cavity diameter of $\beta$-CD is 6.0-7.8 $\AA$; therefore, CD was usually used in separation science and technology because of its unique hollow bowl structure. ${ }^{\mathbf{4 1 , 4 2}}$ 2,3,5,6-tetrafluoroterephthalonitrile (TFTPN, 99\%) was acquired from Matrix Scientific and purified by sublimation under vacuum prior to syntheses. The monomer $5,5^{\prime}, 6,6^{\prime}$-tetrahydroxy-3,3, $3^{\prime}, 3^{\prime}$-tetramethyl-1,1'-spirobisindane (TTSBI, 97\%) was ordered from Alfa Aesar and purified via recrystallization from methanol. The spirocentre within TTSBI is a kinked and shape-persistent ladder structure with a dihedral angle of $90^{\circ} . N, N^{\prime}$-Dimethylformamide (DMF, $>99.5 \%$ ) from Merck (Germany) was further purified via vacuum distillation at $65{ }^{\circ} \mathrm{C}$ before being utilized as the solvent for the polymer synthesis. Anhydrous potassium carbonate $\left(\mathrm{K}_{2} \mathrm{CO}_{3},>99.5 \%\right)$ from Sigma Aldrich, methanol $(\mathrm{MeOH}, \geq 99.9 \%)$ from Merck and dichloromethane (DCM, 99.99\%) and hydrochloric acid $(\mathrm{HCl}, 37.5 \%)$ from Fisher Scientific (UK) were used as received.
All purified gases (at least 99.95\%), such as $\mathrm{C}_{3} \mathrm{H}_{6}, \mathrm{C}_{3} \mathrm{H}_{8}$, and mixed $\mathrm{C}_{3} \mathrm{H}_{6} / \mathrm{C}_{3} \mathrm{H}_{8}(50 \% / 50 \%)$ were supplied by SOXAL Pte. Ltd. (Singapore).

\subsection{Syntheses of polymers and fabrication of membranes}

The typical synthesis procedure of PIM-CD polymers and the fabrication of PIM-CD membranes were carried out according to a previously reported procedure. ${ }^{41}$ PIM-CD-1\% means the molar ratio content of CD is 1 percent in copolymerization. The average membrane thickness was measured from 10 different points using a Digimatic indicator (IDC-112B-5) with an accuracy of $1 \mu \mathrm{m}$. The cast dense membranes with a thickness of about $50 \pm 5 \mu \mathrm{m}$ were used for further studies.

\subsection{Thermal treatment of PIM-CD membranes}

The thermal treatment of PIM and PIM-CD membranes was carried out using a VBF-1200X vacuum furnace from MTI Corporation. The oxygen concentration inside the furnace was measured with an EQ-W3000 Trace Oxygen Analyzer and controlled at about $10 \mathrm{ppm}$ at all times. The vacuum furnace temperature was increased to $100{ }^{\circ} \mathrm{C}$ at a rate of $2{ }^{\circ} \mathrm{C} \mathrm{min} \mathrm{min}^{-1}$ and held for a period of $1 \mathrm{~h}$ to dry the membranes. Subsequently the temperature was increased to a set value at a slow rate of $1{ }^{\circ} \mathrm{C}$ $\min ^{-1}$ in order to prevent the membranes from cracking. Finally, the temperature was held isothermally at the set temperature for $2 \mathrm{~h}$. After the thermal treatment, the membranes were cooled down to room temperature naturally in the vacuum furnace and stored in a dry box for further studies. The thermally treated membranes were labeled as "PIM-CDcontent (temperature)", for example, PIM-CD-1\% $\left(300{ }^{\circ} \mathrm{C}\right)$. A clear coloration from yellow to dark brown and black colors could be observed for the thermally treated membranes depending on the annealing temperature. However, the membranes thermally treated at $700{ }^{\circ} \mathrm{C}$ were extremely fragile, hence leading to enormous difficulties in characterization and sample preparation for permeation tests.

\subsection{Characterization}

The chemical structures of pristine membranes and the thermally treated membranes were analyzed using a Shimadzu Fourier transform infrared spectroscopy (FTIR) 8400 spectrometer in the range of $400-4000 \mathrm{~cm}^{-1}$. The thermogravimetric analyses (TGAs) of pristine membranes were performed by using a Shimadzu Thermal Analyzer (DTG-60AH/TA-60WS/FC$60 \mathrm{~A}$ ) with a heating rate of $10{ }^{\circ} \mathrm{C} \mathrm{m^{-1 }}$ from $50{ }^{\circ} \mathrm{C}$ to $800{ }^{\circ} \mathrm{C}$ under a nitrogen atmosphere with a flow rate of $50 \mathrm{~mL} \mathrm{~min}{ }^{-1}$. The TGA outlet was coupled on-line with a Perkin-Elmer FTIR Spectra 2000 spectrometer. Thus, the exhausted products from the TGA were analyzed in a gas cell and the IR spectra were obtained by using a $\mathrm{KBr}$ beam splitter. The decomposition process of PIM-CD membranes was recorded over the range of $50-800{ }^{\circ} \mathrm{C}$.

The insoluble content of the thermally treated membranes was determined by soaking the respective membranes in a DCM solvent for $24 \mathrm{~h}$. The remaining insoluble portions of the membranes were dried under vacuum at $120{ }^{\circ} \mathrm{C}$ for $24 \mathrm{~h}$ to 
remove the residual solvent before weighing. The insoluble content was evaluated using eqn (1):

$$
\% \text { insoluble content }=M_{1} / M_{0} \times 100
$$

where $M_{0}$ and $M_{1}$ are the weights of the thermally treated membrane before and after soaking in DCM, respectively.

The inter-chain spacing of the membranes was investigated by using a Bruker D8 Advance X-ray diffractometer (XRD) utilizing Cu $\mathrm{K}-\alpha$ as the X-ray radiation source with a wavelength of $1.54 \AA$. The $\mathrm{X}$-ray diffraction angles between 5 and 30 were studied. The average $d$-spacing was evaluated based on Bragg's law $(n \lambda=$ $2 d \sin \theta$ ), where $n$ is an integer $(1,2,3, \ldots), l$ represents the X-ray wavelength, $d$ represents the intersegmental spacing between two polymer chains and $\theta$ denotes the X-ray diffraction angle.

\subsection{Measurements of gas permeation}

The gas permeation properties for both pure gases and mixed gases were determined on a variable-pressure constant-volume gas permeation cell. The detailed experimental design and procedures have been reported by our group. ${ }^{\mathbf{4 1 , 4 6}}$ The dense membrane was mounted onto the permeation cell and vacuumed at $35^{\circ} \mathrm{C}$ for $12 \mathrm{~h}$ before tests. Pure gas permeability was tested following the order of $\mathrm{C}_{3} \mathrm{H}_{6}$ and $\mathrm{C}_{3} \mathrm{H}_{8}$. The cell temperature was kept constant at $35{ }^{\circ} \mathrm{C}$. The permeability tests were repeated at least three times for three different samples prepared under the same conditions and the average deviation obtained was less than $5 \%$.

The ideal selectivity between two different gases across a polymeric membrane is the ratio of their single gas permeability as described in the following eqn (2):

$$
\alpha_{\mathrm{A} / \mathrm{B}}=\frac{P_{\mathrm{A}}}{P_{\mathrm{B}}}
$$

where $P_{\mathrm{A}}$ and $P_{\mathrm{B}}$ refer to the permeability coefficients of gases A and $\mathrm{B}$, respectively. According to the solution-diffusion model, permeability is the product of diffusivity $(D)$ and solubility $(S)$. Therefore, the ideal permeability selectivity $\left(\alpha_{\mathrm{P}}\right)$ can be defined as the product of diffusivity selectivity $\left(\alpha_{\mathrm{D}}\right)$ and solubility selectivity $\left(\alpha_{\mathrm{S}}\right)$ as described in eqn (3) and (4):

$$
\begin{gathered}
P=D \times S \\
\alpha_{\mathrm{A} / \mathrm{B}}=\alpha_{\mathrm{P}}=\alpha_{\mathrm{D}} \times \alpha_{\mathrm{S}}=\frac{D_{\mathrm{A}}}{D_{\mathrm{B}}} \times \frac{S_{\mathrm{A}}}{S_{\mathrm{B}}}
\end{gathered}
$$

where $D_{\mathrm{A}}$ and $D_{\mathrm{B}}$ are the diffusion coefficients of gases A and B, respectively $\left(\mathrm{cm}^{2} \mathrm{~s}^{-1}\right) ; S_{\mathrm{A}}$, and $S_{\mathrm{B}}$ are the solubility coefficients of gases A and $\mathrm{B}$, respectively $\left(\mathrm{cm}^{3}\right.$ (STP) $\mathrm{cm}^{-3}$ polymer atm). In the case of mixed gas experiments, a binary mixture of $50 \% \mathrm{C}_{3} \mathrm{H}_{6}$ and $50 \% \mathrm{C}_{3} \mathrm{H}_{8}$ was used. The membranes were tested at $35{ }^{\circ} \mathrm{C}$ with a feed pressure of 3,5 and $7 \mathrm{~atm}$. The mixed gas composition was analyzed by using a Hewlett Packard (HP) 6890 Series gas chromatograph (GC) integrated with a HP 5973 mass selective detector.

\subsection{Measurements of gas sorption}

Pure gas sorption of the thermally treated membranes was measured via the dual-volume pressure decay method using a XEMIS microbalance system. ${ }^{41}$ The membranes weighing about $50-60 \mathrm{mg}$ were placed into the sample chamber and a vacuum was maintained for $3 \mathrm{~h}$ before sorption tests were conducted. Both the reference and sample chambers were immersed in the same water bath ((Techne FTE-10DE) from Techne Cambridge LTD (UK) with an accuracy of $\pm 0.01^{\circ} \mathrm{C}$ ) to maintain the desired temperature. The sorption isotherm of each gas was obtained at $35{ }^{\circ} \mathrm{C}$ up to a maximum pressure of 5 atm. Sorption tests were conducted for $\mathrm{C}_{3} \mathrm{H}_{6}$ and $\mathrm{C}_{3} \mathrm{H}_{8}$ pure gases.

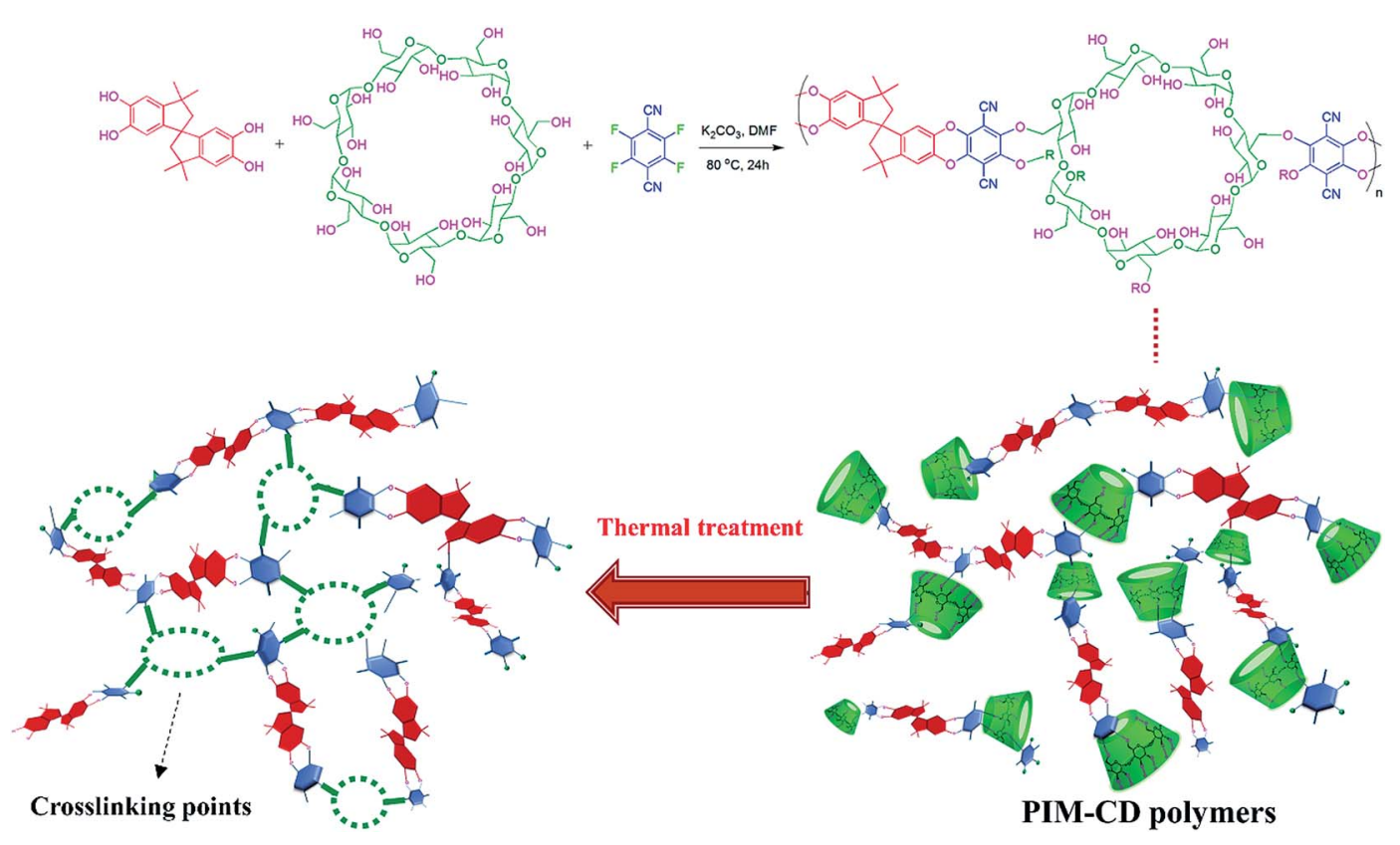

Fig. 1 Synthesis and thermal crosslinking schemes of PIM-CD polymers. 


\section{Results and discussion}

\subsection{Characterization of the polymer membranes}

As presented in Fig. 1, the 3D PIM-CD polymer precursors were synthesized via nucleophilic substitution copolymerization of $\beta$ CD, TFTPN, and TTSBI. Since $\beta$-CD comprises multiple reactive hydroxyl groups, it can be copolymerized into the main chains of PIM easily. The copolymerization was conducted in a polar aprotic anhydrous solvent of DMF at $80{ }^{\circ} \mathrm{C}$ for $24 \mathrm{~h}$, using $\mathrm{K}_{2} \mathrm{CO}_{3}$ as the catalyst. The chemical structures of the original PIM and PIM-CD polymers were characterized and confirmed in our previous report. ${ }^{41}$ The thermal stability of the original PIM and PIM-CD membranes was evaluated by TGA. Fig. 2 shows their

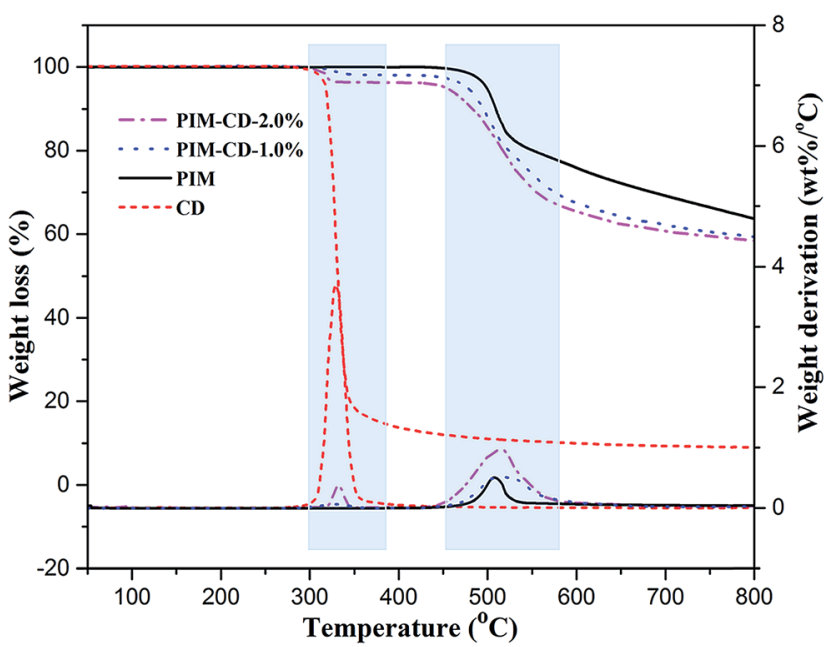

Fig. 2 TGA spectra of $\beta-C D$, pristine PIM and PIM-CD membranes. thermal decomposition and derivatives of weight losses (e.g. decomposition rates) as a function of temperature in a nitrogen atmosphere. Pure $\beta$-CD is also included in TGA tests for comparison; it decomposes from about 300 to $400{ }^{\circ} \mathrm{C}$. Compared to the pristine PIM membrane, the PIM-CD membranes exhibit a little lower thermal stability due to the weight loss of $\beta$-CD in their polymer chains. There are two stages of thermal degradation for PIM-CD membranes. The first stage of weight loss starts from $300{ }^{\circ} \mathrm{C}$ to $400{ }^{\circ} \mathrm{C}$ and the amount of weight loss increases with increasing CD loading, while the second stage of weight loss from $450{ }^{\circ} \mathrm{C}$ is attributed to the decomposition of the PIM polymer chains.

Fig. 3 presents the simultaneous 2D FTIR spectra of pyrolysis gases evolved from the membranes during TGA tests. Three major fragments are found in the decomposition of pure $\beta$-CD due to the rupture initiated from the $\mathrm{C}-\mathrm{O}$ and $\mathrm{C}-\mathrm{C}$ bonds in glucose units of $\beta$-CD. The release of compounds at about 3600 , 2350 and $1750 \mathrm{~cm}^{-1}$ may be characteristic bands of $\mathrm{OH}, \mathrm{CO}_{2}$ and $\mathrm{C}_{x} \mathrm{H}_{y} \mathrm{O}$ (aldehydes or ketones), respectively. In addition, there is no other IR peak during the decomposition of pure $\beta$ CD. Only the CD structure decomposition contributes to the weight loss of the PIM-CD membranes during the first stage of weight loss from 300 to $400{ }^{\circ} \mathrm{C}$. Compared with pure $\beta$-CD, the PIM-CD-1\% and PIM-CD-2\% have new characteristic peaks at about $3050(\mathrm{C}-\mathrm{H})$ and $1500 \mathrm{~cm}^{-1}(\mathrm{C} \equiv \mathrm{N})$. These $\mathrm{C}-\mathrm{H}$ fragments arise mainly from the decomposition of methyl groups, while the $\mathrm{C} \equiv \mathrm{N}$ fragments come from nitrile groups of PIM in the range of $400-600{ }^{\circ} \mathrm{C}$. Clearly, the $\beta$-CD will decompose to form microvoids and cross-linking points when the membranes are treated at $300-400{ }^{\circ} \mathrm{C}$, while the PIM polymer chains will decompose or partially carbonize when the membranes are treated at 500-600 ${ }^{\circ} \mathrm{C}$. As shown in Fig. 4, after thermal
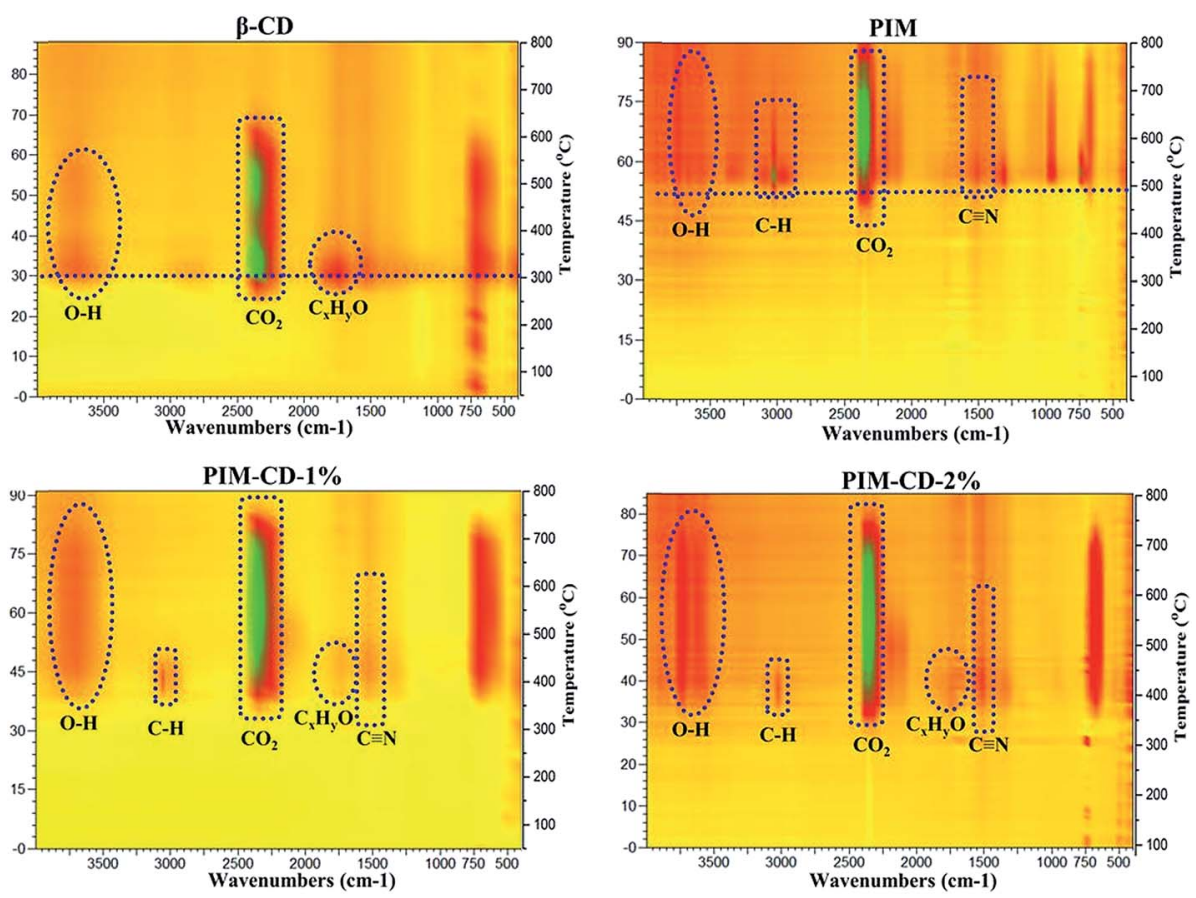

Fig. 3 FTIR-TGA spectra of $\beta-C D$, pristine PIM and PIM-CD membranes. 

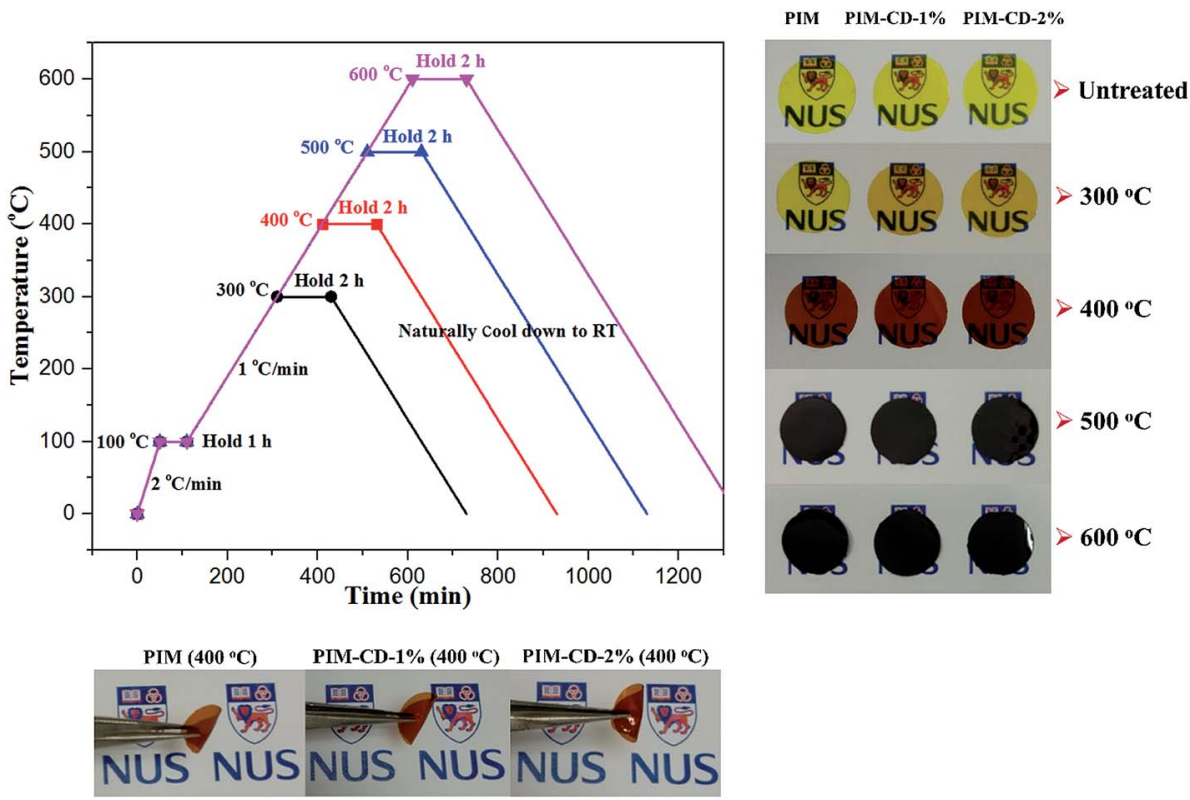

Fig. 4 Photographs and thermal treatment procedures of PIM-CD membranes.

treatments, the transparent membranes change from the original fluorescent yellow to dark brown at $400^{\circ} \mathrm{C}$ and then to deep black at $500{ }^{\circ} \mathrm{C}$. The PIM-CD membranes treated at $300{ }^{\circ} \mathrm{C}$ are slightly darker than the PIM membrane because of little more cross-linking points induced by $\beta$-CD and more formation of inter-chain charge transfer complexes (CTCs). All membranes thermally treated at and below $400{ }^{\circ} \mathrm{C}$ are flexible and can be bended tightly, while the membranes thermally treated at and above $500{ }^{\circ} \mathrm{C}$ are fragile.

The chemical structure changes and the formation of triazine after thermal treatment were confirmed by FTIR-ATR and XPS analyses. As illustrated in Fig. 5, the characteristic absorption at $2239 \mathrm{~cm}^{-1}$ is assigned to the stretching of $\mathrm{C} \equiv \mathrm{N}$

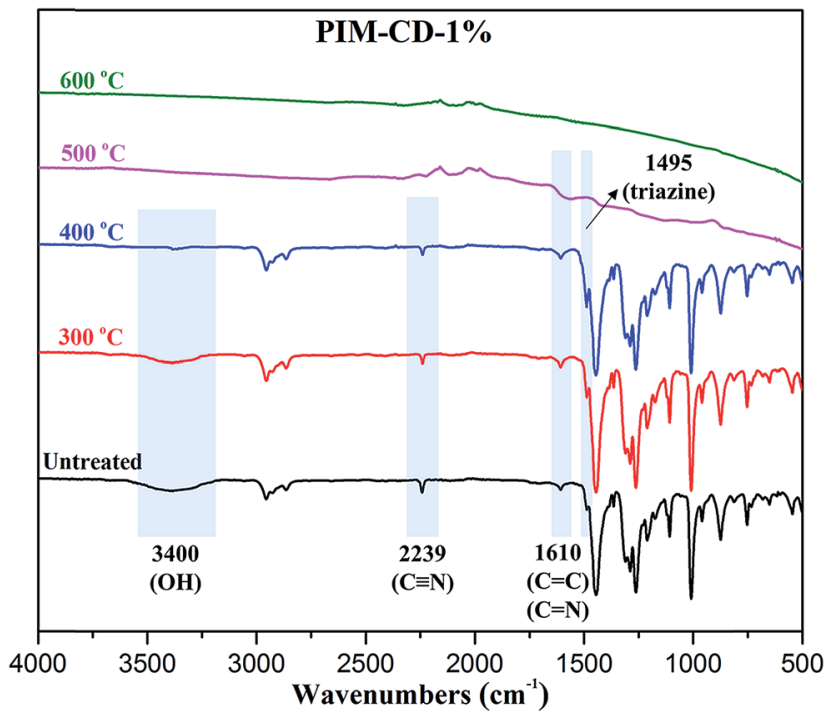

Fig. 5 FTIR-ATR spectra of the membranes after thermal treatment. groups. The broad band at $3400 \mathrm{~cm}^{-1}$ is attributed to the $\mathrm{O}-\mathrm{H}$ groups in PIM-CD polymers. The intensity of both $\mathrm{C} \equiv \mathrm{N}$ and $\mathrm{O}-\mathrm{H}$ peaks decrease dramatically with increasing the annealing temperature. In contrast, the intensity at $1495 \mathrm{~cm}^{-1}$ attributed to the triazine ring slightly increases due to the thermal selfcross-linking of $\mathrm{C} \equiv \mathrm{N}$ groups. ${ }^{38}$ Additionally, the $\mathrm{C}=\mathrm{C}$ bonds persist when the thermal treatment temperature is lower than the decomposition temperature of PIM polymer chains, while the $\mathrm{C}=\mathrm{N}$ bonds are gradually generated from the thermal selfcross-linking of $\mathrm{C} \equiv \mathrm{N}$ groups. Since the characteristic peaks of both the $\mathrm{C}=\mathrm{C}$ stretching of aromatic rings and the $\mathrm{C}=\mathrm{N}$ stretching of the triazine ring fall in approximately the same position $1610 \mathrm{~cm}^{-1}$, the intensity of the absorption at 1610 $\mathrm{cm}^{-1}$ increases a little with increasing the thermal treatment temperature. There are no obvious peaks of the membranes thermally treated at 500 or $600{ }^{\circ} \mathrm{C}$, probably because of the weak IR reflection of dark black membranes due to partial carbonization and formation of carbon molecular sieves.

Besides, XPS analyses were also applied to confirm the thermal cross-linking process and the generation of the triazine ring. Fig. 6 depicts the XPS spectra of the original and thermally treated membranes. The original PIM-CD-1\% membrane presents a symmetrical Gaussian-type $\mathrm{N}_{1 \mathrm{~s}}$ core signal with the maximum peak at $398.3 \mathrm{eV}$ which is ascribed to the $\mathrm{C} \equiv \mathrm{N}$ (nitrile) groups of the PIM polymer chains. After thermal treatment, the symmetrical $\mathrm{N}_{1 \mathrm{~s}}$ signal becomes broader and asymmetrical with a newly formed shoulder peak at about $399.5 \mathrm{eV}$, which is assigned to the nitrogen of $\mathrm{C}=\mathrm{N}$ groups in the thermally self-cross-linked triazine ring. In order to quantitatively detect the degree of the thermally self-cross-linking reaction, the $\mathrm{N}_{1 \mathrm{~s}}$ XPS spectrum was deconvoluted into two peaks at 398.3 and $399.5 \mathrm{eV}$. In addition, the highest peak at 402.5 is probably due to the $\pi$-excitation which appears in all carbon compounds with double bonds. The ratio of integrated 

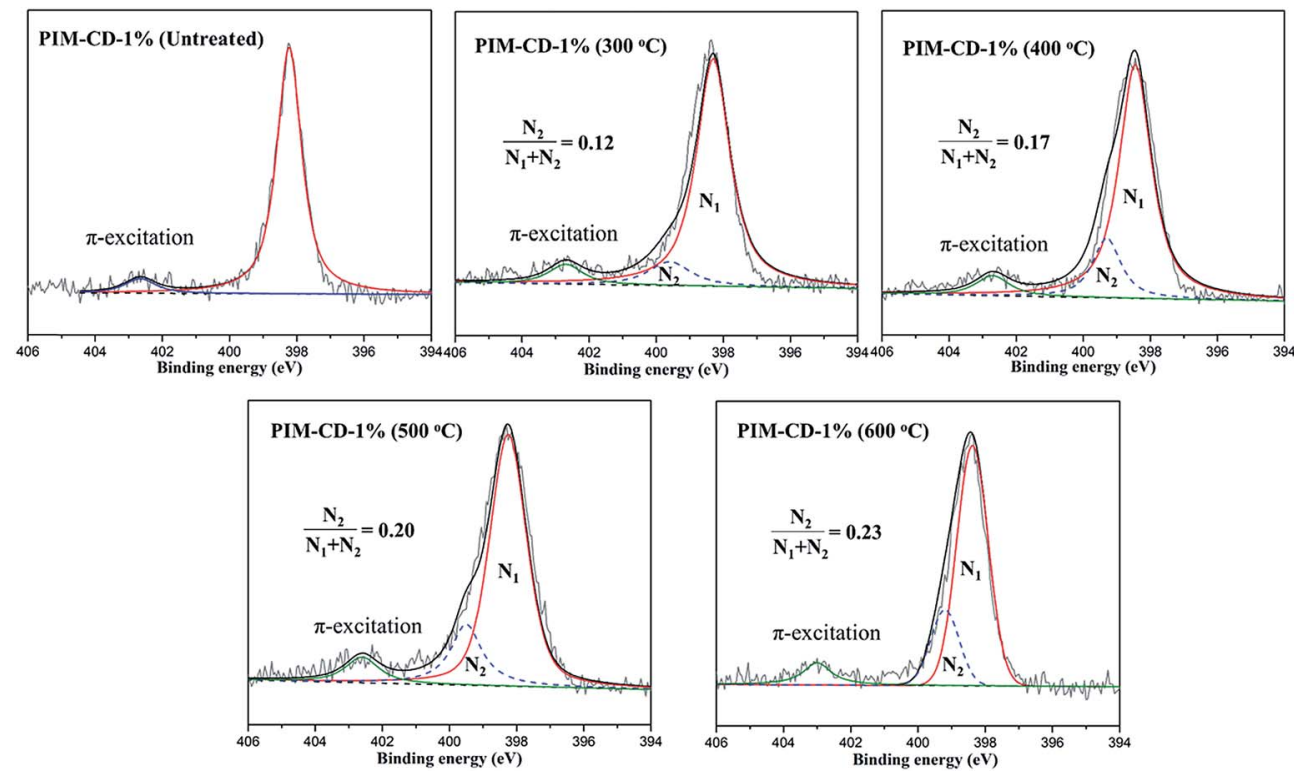

Fig. $6 \quad N_{1 s}$ XPS analyses of the untreated and thermally treated PIM-CD-1\% membranes.

area $\mathrm{C}=\mathrm{N} / \mathrm{C} \equiv \mathrm{N}+\mathrm{C}=\mathrm{N}\left(\right.$ i.e., $\left.\mathrm{N}_{2} /\left(\mathrm{N}_{1}+\mathrm{N}_{2}\right)\right)$ shows an increasing trend from 0.12 to 0.23 with an increase in the thermal treatment temperature. This suggests that the content of the thermal cross-linking triazine ring is more pronounced at a higher temperature. The direct evidence for the inter-chain crosslinking reaction is the color change of the membrane from the original fluorescent yellow to dark brown and then to deep black. During the thermal treatment process, $\beta$-CD units first decompose to generate free radicals, which can effectively accelerate the self-cross-linking reaction of nitrile. The formation of triazine rings tends to pull the PIM polymer chains closely together and allows the transfer of $\pi$-electrons from the electron donors (i.e., ether groups) to the electron acceptor (i.e., triazine ring). Thus, charge-transfer complexes between the polymer chains are formed that generates the dark colors.

A direct indication of the occurrence and the extension of the self-cross-linking reaction at different treatment temperatures is provided by the insoluble content of the membranes. As observed from Fig. 7, the degree of the self-cross-linking reaction increases with increasing the thermal treatment
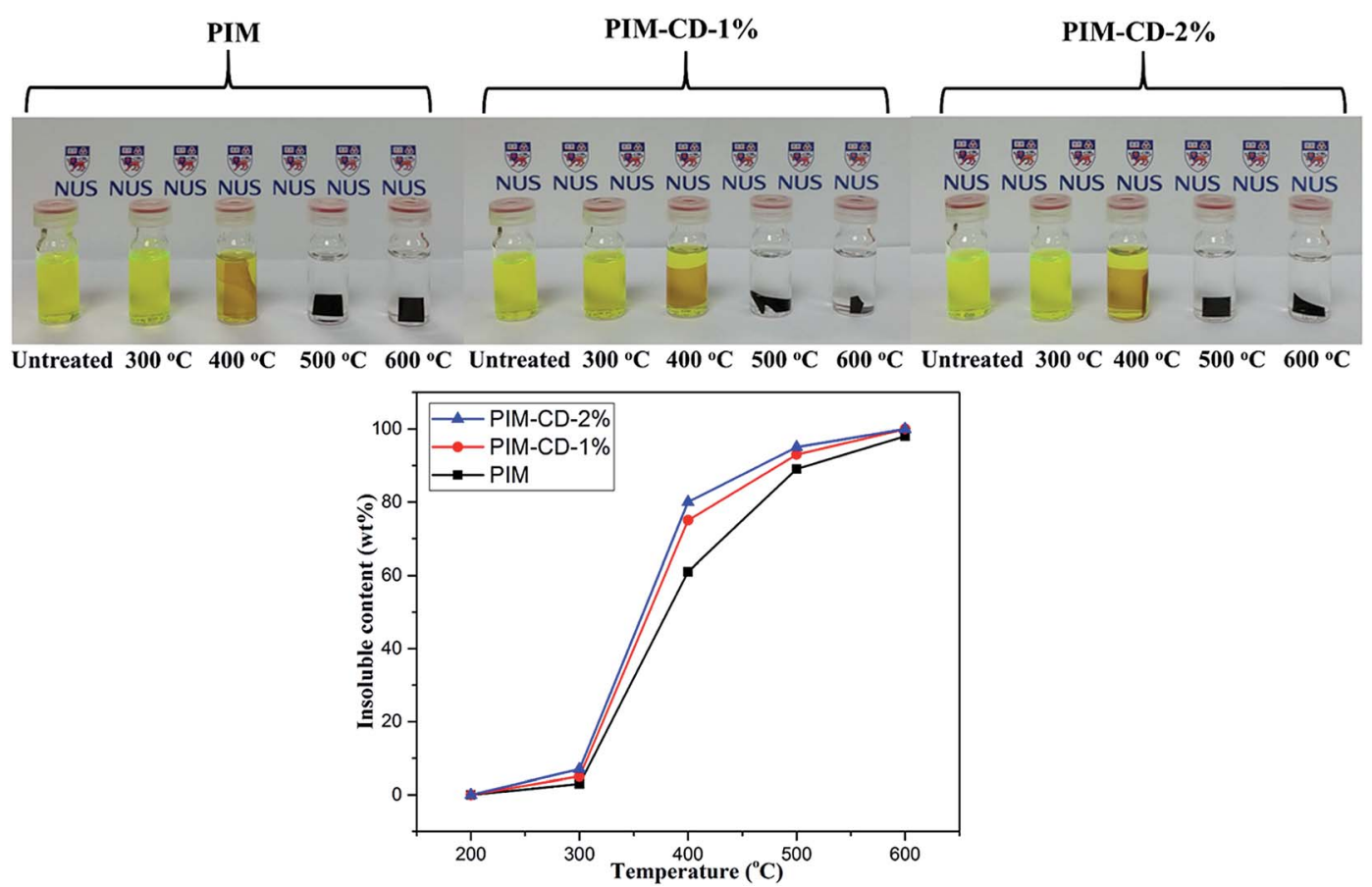

Fig. 7 The insoluble content of membranes treated at different temperatures and then soaked in DCM for 24 hours. 


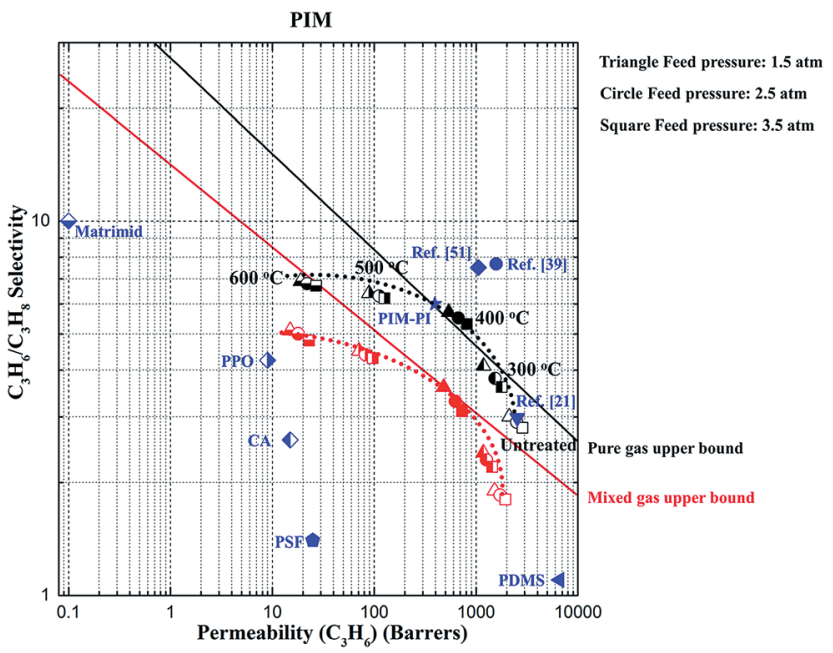

Fig. 8 Comparison of the pure and mixed gas performance of the thermally treated PIM membranes at $35{ }^{\circ} \mathrm{C}$ (lines are drawn to guide the eyes).

temperature. Clearly, there is more than $89 \%$ insoluble content for the membranes treated above $500{ }^{\circ} \mathrm{C}$, the thermally crosslinked membranes are largely insoluble in DCM even after 24 hour immersion. Additionally, the insoluble content of PIM-CD membranes is higher than those of pristine PIM membranes, and the free radicals generated from $\beta$-CD decomposition can effectively facilitate the self-cross-linking reaction of nitrile.

\subsection{Pure and mixed gas separation performance}

Fig. 8 plots the pure and mixed gas separation performance against their corresponding upper bound lines. ${ }^{3}$ The previously reported data of PIM-1, PIM-PI and commercial polymers for propylene/propane separation are also included in Table 2 and the Robeson plot. The gas separation performance of the thermally treated PIM-CD membranes is better than those of commercial polymeric membranes. ${ }^{43-45}$ In this study, for both pure and mixed gas tests, the thermally treated membranes have a higher selectivity than the original untreated ones, while the $\mathrm{C}_{3} \mathrm{H}_{6}$ permeability measured in mixed gases is always lower than that in pure gas because of competitive sorption of $\mathrm{C}_{3} \mathrm{H}_{6}$ and $\mathrm{C}_{3} \mathrm{H}_{8}$ in the membranes. Except the PIM membrane annealed at $400{ }^{\circ} \mathrm{C}$, no other annealed PIM membranes can surpass the upper bound lines in either pure or mixed gas tests. In contrast, the thermally treated PIM-CD-1\% membranes at 300 and $400{ }^{\circ} \mathrm{C}$ can all surpass the upper bound lines, as illustrated in Fig. 9.

Fig. 10 also shows the gas separation performance of the thermally treated PIM-CD-2\% membranes against the upper bound lines. The $\mathrm{C}_{3} \mathrm{H}_{6} / \mathrm{C}_{3} \mathrm{H}_{8}$ selectivity increases with increasing the thermal treatment temperature and generally follows the order of PIM-CD-2\% $\left(600{ }^{\circ} \mathrm{C}\right)>$ PIM-CD- $\%\left(500{ }^{\circ} \mathrm{C}\right)$ $>$ PIM-CD-2\% $\left(400{ }^{\circ} \mathrm{C}\right)>$ PIM-CD- $\%\left(300{ }^{\circ} \mathrm{C}\right)$, while the gas permeability decreases and follows the opposite order. Interestingly, the PIM-CD-2\% membranes thermally treated at 300, 400 and $500{ }^{\circ} \mathrm{C}$ can all surpass the upper bound line for mixed gas separation. Since the main released gases derived from $\mathrm{CD}$ decomposition are $\mathrm{C}_{2} / \mathrm{C}_{3}$ compounds (Fig. 3) which have similar sizes with $\mathrm{C}_{3} \mathrm{H}_{6}$ and $\mathrm{C}_{3} \mathrm{H}_{8}$, the transport channels resulted from CD's decomposition may possess the appropriate characteristics to discriminate $\mathrm{C}_{3} \mathrm{H}_{6}$ and $\mathrm{C}_{3} \mathrm{H}_{8}$, thus improving the gas pair selectivity. ${ }^{4-49}$ In other words, the decomposition of thermal liable $\beta$-CD at high temperatures would generate free radicals and effectively accelerate the self-cross-linking reaction of nitrile to form triazine rings and pull the polymer chains closely

Table 1 Permeability, solubility and diffusion coefficients of the thermally treated membranes at 3.5 atm and $35^{\circ} \mathrm{C}$

\begin{tabular}{|c|c|c|c|c|c|c|c|c|c|}
\hline \multirow[b]{2}{*}{ Membranes } & \multicolumn{2}{|c|}{$\begin{array}{l}\text { Pure gas } \\
\text { permeability } \\
\text { (barrer) }\end{array}$} & \multirow{2}{*}{$\begin{array}{l}\text { Permeability } \\
\text { selectivity }\end{array}$} & \multicolumn{2}{|c|}{$\begin{array}{l}\text { Solubility } \\
\text { coefficient }\left(\mathrm{cm}^{3}\right. \\
\left.\mathrm{cm}^{-3} \mathrm{~cm} \mathrm{Hg}^{-1}\right) \\
\end{array}$} & \multirow{2}{*}{$\begin{array}{l}\text { Solubility } \\
\text { selectivity }\end{array}$} & \multicolumn{2}{|c|}{$\begin{array}{l}\text { Diffusion } \\
\text { coefficient }\left(10^{-10}\right. \\
\left.\mathrm{cm}^{2} \mathrm{~s}^{-1}\right)\end{array}$} & \multirow{2}{*}{$\begin{array}{l}\text { Diffusivity } \\
\text { selectivity }\end{array}$} \\
\hline & $\mathrm{C}_{3} \mathrm{H}_{6}$ & $\mathrm{C}_{3} \mathrm{H}_{8}$ & & $\mathrm{C}_{3} \mathrm{H}_{6}$ & $\mathrm{C}_{3} \mathrm{H}_{8}$ & & $\mathrm{C}_{3} \mathrm{H}_{6}$ & $\mathrm{C}_{3} \mathrm{H}_{8}$ & \\
\hline PIM (untreated) & 2861 & 1022 & 2.80 & 0.45 & 0.41 & 1.10 & 6358 & 2493 & 2.55 \\
\hline $\operatorname{PIM}\left(300^{\circ} \mathrm{C}\right)$ & 1792 & 498 & 3.60 & 0.43 & 0.38 & 1.13 & 4167 & 1311 & 3.18 \\
\hline $\operatorname{PIM}\left(400^{\circ} \mathrm{C}\right)$ & 817 & 154 & 5.31 & 0.37 & 0.33 & 1.12 & 2208 & 467 & 4.73 \\
\hline $\operatorname{PIM}\left(500^{\circ} \mathrm{C}\right)$ & 127 & 20 & 6.35 & 0.33 & 0.27 & 1.22 & 385 & 74 & 5.20 \\
\hline $\operatorname{PIM}\left(600{ }^{\circ} \mathrm{C}\right)$ & 27 & 4 & 6.75 & 0.45 & 0.37 & 1.22 & 59 & 11 & 5.36 \\
\hline PIM-CD-1\% (untreated) & 4315 & 1725 & 2.50 & 0.46 & 0.43 & 1.07 & 9380 & 4012 & 2.34 \\
\hline PIM-CD-1\% $\left(300^{\circ} \mathrm{C}\right)$ & 2942 & 817 & 3.60 & 0.44 & 0.39 & 1.13 & 6686 & 2095 & 3.19 \\
\hline PIM-CD-1\% $\left(400^{\circ} \mathrm{C}\right)$ & 1217 & 214 & $\begin{array}{l}3.00 \\
5.69\end{array}$ & 0.40 & 0.35 & 1.14 & 3042 & 611 & 4.98 \\
\hline PIM-CD-1\% $\left(500^{\circ} \mathrm{C}\right)$ & 122 & 18 & $\begin{array}{l}5.09 \\
6.78\end{array}$ & 0.29 & 0.25 & $\begin{array}{l}1.14 \\
1.16\end{array}$ & 421 & 72 & 5.85 \\
\hline PIM-CD-1\% $\left(600^{\circ} \mathrm{C}\right)$ & 22 & 3 & 7.33 & 0.35 & 0.29 & 1.21 & 63 & 10 & 6.30 \\
\hline PIM-CD-2\% (untreated) & 5032 & 2097 & 2.40 & 0.47 & 0.45 & 1.04 & 10706 & 4660 & 2.30 \\
\hline PIM-CD-2\% $\left(300^{\circ} \mathrm{C}\right)$ & 3642 & 958 & 3.80 & 0.44 & 0.38 & 1.16 & 8277 & 2521 & 3.28 \\
\hline PIM-CD- $2 \%\left(400{ }^{\circ} \mathrm{C}\right)$ & 2093 & 403 & 5.19 & 0.39 & 0.33 & 1.18 & 5367 & 1221 & 4.40 \\
\hline PIM-CD- $2 \%\left(500{ }^{\circ} \mathrm{C}\right)$ & 192 & 27 & 7.11 & 0.37 & 0.31 & 1.19 & 519 & 87 & 5.97 \\
\hline PIM-CD- $2 \%\left(600{ }^{\circ} \mathrm{C}\right)$ & 42 & 5 & 8.40 & 0.41 & 0.32 & 1.28 & 102 & 16 & 6.38 \\
\hline
\end{tabular}


Table 2 A comparison of the $\mathrm{C}_{3} \mathrm{H}_{6} / \mathrm{C}_{3} \mathrm{H}_{8}$ transport properties with those of previously reported PIM-1, PIM-PI and commercial polymers ${ }^{a}$

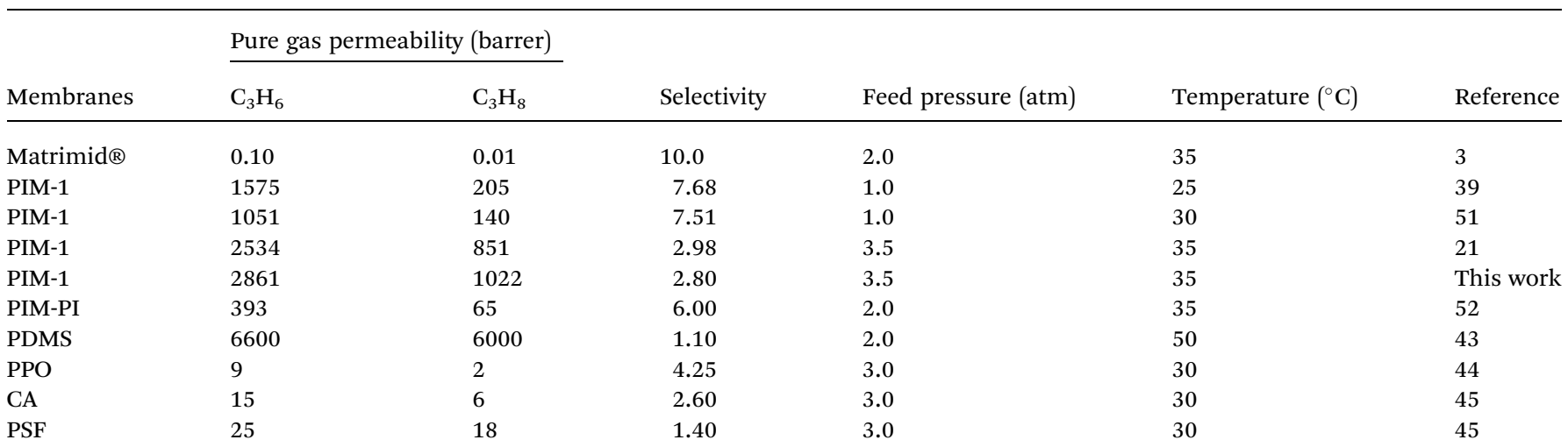

${ }^{a}$ Note: polydimethylsiloxane (PDMS), cellulose acetate (CA), polysulfone (PSF), poly(2,6-dimethyl-1,4-phenylene oxide) (PPO), the date of CA and PSF in ref. 45 were tested using a mixed gas containing $55 \%$ propylene and $45 \%$ propane.

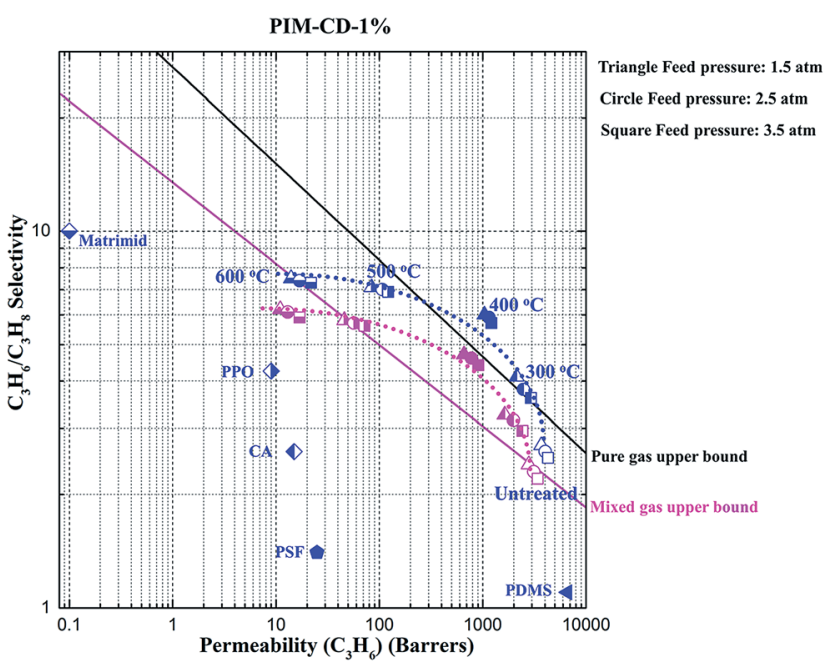

Fig. 9 Comparison of the pure and mixed gas performance of the thermally treated PIM-CD-1\% membranes at $35^{\circ} \mathrm{C}$ (lines are drawn to guide the eyes).

together. This results in a three-dimensional cross-linked network with narrow gates that not only offer a better size and shape selectivity but also keep the overall permeability sufficiently high for rapid diffusion of gas molecules. Therefore, the gas selectivity of the membranes treated at and below $400{ }^{\circ} \mathrm{C}$ increases rapidly while their gas permeability just decreases slightly compared to that of the original untreated one.

There are two competing factors influencing the gas permeability. The positive one is the provision of super highways by the $\mathrm{CD}$ units for gas transport, while the negative one is the shrinkage of the microspores when annealed at high temperatures. As observed from the TGA spectra, only CD decomposes during the first stage of weight loss from 300 to $400{ }^{\circ} \mathrm{C}$. Clearly, after the $\mathrm{CD}$ decomposition, the spaces originally occupied by $\mathrm{CD}$ convert to micro-pores, which provide highways for gas transport. On the other hand, the heat treatment densifies the polymer chains, which is a negative factor for gas transport. When the annealing temperature increases to $500{ }^{\circ} \mathrm{C}$ or higher (above the glass transition temperature of PIM), the polymer chains tend to pack more densely. Crosslinking reactions and partial carbonization may also occur that shrink the micropores to ultrafine micropores with pore dimensions able to discriminate the $\mathrm{C}_{3} \mathrm{H}_{6} / \mathrm{C}_{3} \mathrm{H}_{8}$ gas pair. Since gas selectivity is mainly determined by ultra-fine micro-pores, while gas permeability is largely related to the micro-pores, the gas permeability of PIM-CD membranes decreases while their selectivity increases with an increase in the thermal treatment temperature.

Fig. 11 shows the evolution of the $d$-spacing of the polymer chains as a function of thermal treatment temperature. The untreated PIM-CD-1\% membrane has a peak at about $6.6 \AA$ which is probably attributed to the loosely packed polymer chains derived from the kinked ladder-type backbone of PIM because of the formation of micro-pores among the polymer chains..$^{50}$ The next peak at $4.9 \AA$ is the $d$-spacing of the efficiently packed

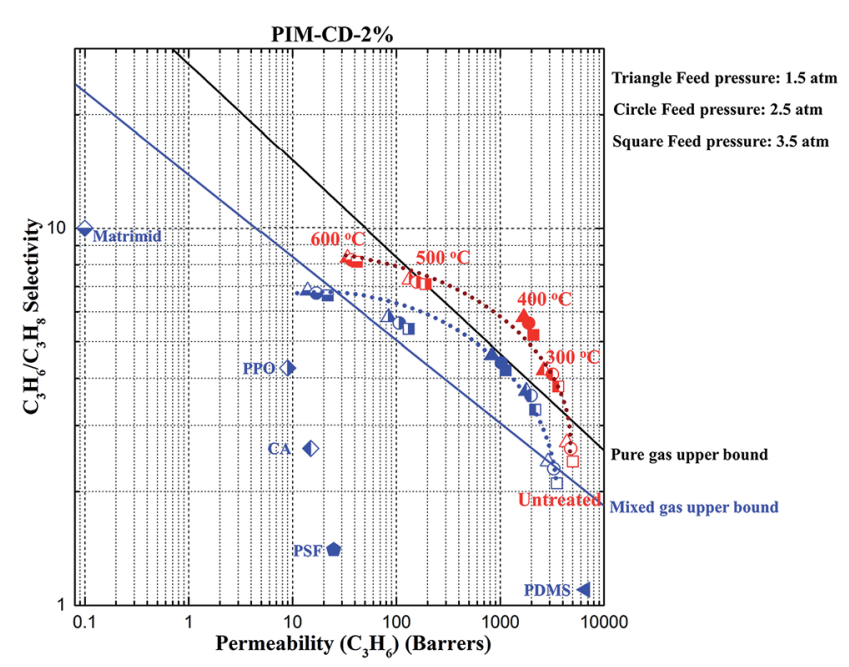

Fig. 10 Comparison of the pure and mixed gas performance of the thermally treated PIM-CD- $2 \%$ membranes at $35^{\circ} \mathrm{C}$ (lines are drawn to guide the eyes). 


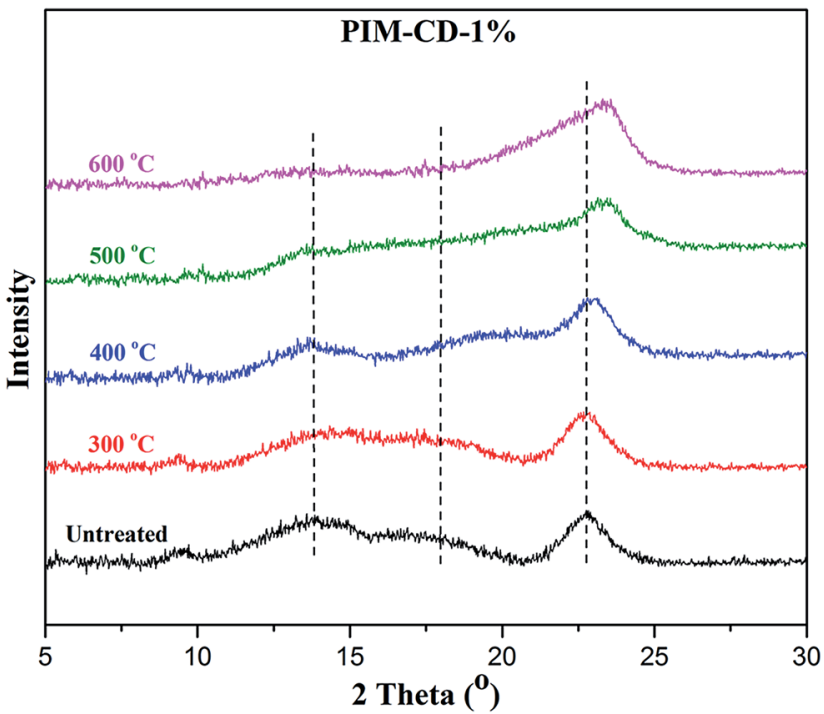

Fig. 11 XRD spectra of the untreated and thermally treated PIM-CD$1 \%$ membranes.

polymer chain-to-chain distance that contributes directly to the conformation of small micro-pores. After thermal treatment, the two peaks at 6.6 and $4.9 \AA$ gradually shrink with increasing annealing temperature. They almost disappear when the annealing temperature increases to 500 or $600{ }^{\circ} \mathrm{C}$ (i.e., above the glass transition temperature of PIM). These suggest the densification of the polymer chains and the occurrence of the self-cross-linking reaction or partial carbonization in the membrane. As a result, the micropores shrink to ultra-fine micropores. However, the last peak at $3.8 \AA$ is always there regardless of the annealing temperature because it is a typical peak for aromatic systems and amorphous carbon configurations. The kinetic diameters of propylene and propane are about 4.0 and $4.2 \AA$, respectively. The ultra-fine micropores with a size about 4.1-3.5 ^ (a broad distribution near $3.8 \AA$ ) play an important role as molecular sieves for propylene/propane separation. The thermally liable $\beta-C D$ decomposes to generate free radicals after thermal treatment, which can effectively accelerate the self-cross-linking reaction of nitrile. The resultant 3D cross-linking networks have narrow gates as molecular sieves with better size and shape exclusion for propylene/propane separation. Clearly, the XRD results support our previous observation that the permeability always decreases while the $\mathrm{C}_{3} \mathrm{H}_{6} / \mathrm{C}_{3} \mathrm{H}_{8}$ selectivity increases with an increase in the thermal treatment temperature.

\subsection{Gas sorption isotherms}

The pure gas sorption isotherms of the untreated and thermally treated membranes at $35{ }^{\circ} \mathrm{C}$ up to 5 atm are illustrated in Fig. 12. For the same gas either $\mathrm{C}_{3} \mathrm{H}_{6}$ or $\mathrm{C}_{3} \mathrm{H}_{8}$, the amount of gas sorption obeys the order of PIM-CD-2\% > PIM-CD-1\% > PIM because the addition of $\mathrm{CD}$ into membranes creates more micro-pores and free volume to capture gas molecules regardless of thermal treatment, while for the same membrane, the sorption amount is in the order of $\mathrm{C}_{3} \mathrm{H}_{6}>\mathrm{C}_{3} \mathrm{H}_{8}$, following the exact order of their condensability (i.e., critical temperatures).
The PIM-CD membranes annealed at $300{ }^{\circ} \mathrm{C}$ have slightly lower $\mathrm{C}_{3} \mathrm{H}_{6}$ and $\mathrm{C}_{3} \mathrm{H}_{8}$ sorption concentrations than the untreated ones because of partial CD decomposition and slight chain densification at this temperature. When the annealing temperature is $400{ }^{\circ} \mathrm{C}$, almost all CD decomposes but the $\mathrm{C}_{3} \mathrm{H}_{6}$ and $\mathrm{C}_{3} \mathrm{H}_{8}$ sorption concentrations are further reduced due to a greater degree of chain densification.

When the thermal treatment temperature is increased to 500$600{ }^{\circ} \mathrm{C}$, the gas sorption isotherms present an interesting behavior. The $\mathrm{C}_{3} \mathrm{H}_{6}$ and $\mathrm{C}_{3} \mathrm{H}_{8}$ sorption concentrations increase quickly at low pressures, and then reach plateaus rapidly. Obviously, the total sorption amounts of $\mathrm{C}_{3} \mathrm{H}_{6}$ and $\mathrm{C}_{3} \mathrm{H}_{8}$ in the untreated membranes at $5 \mathrm{~atm}$ are higher than those in the $600{ }^{\circ} \mathrm{C}$ treated membranes. This is probably due to the partial carbonization of the PIM polymer chains that shrinks the micropores to ultrafine micropores during the pyrolysis. The sorption behavior of the carbonized membranes $\left(600^{\circ} \mathrm{C}\right)$ is in agreement with the Langmuir mode because it behaves like a hole-filling process (i.e., the ultrafine micropores are filled with $\mathrm{C}_{3} \mathrm{H}_{6}$ or $\mathrm{C}_{3} \mathrm{H}_{8}$ rapidly at low pressures) and there is a sorption capacity limitation for each gas. The change of free volume could approximately be evaluated from the gas sorption isotherms. The free volume gradually shrinks according to the reduced $\mathrm{C}_{3} \mathrm{H}_{6} / \mathrm{C}_{3} \mathrm{H}_{8}$ gas sorption capability after the thermal treatment.

Since the amorphous carbon sheets may have strong $\pi-\pi$ interactions with $\mathrm{C}_{3} \mathrm{H}_{6}$ and $\mathrm{C}_{3} \mathrm{H}_{8}$, the carbonized membranes thermally treated at $600{ }^{\circ} \mathrm{C}$ have higher sorption concentrations of $\mathrm{C}_{3} \mathrm{H}_{6}$ and $\mathrm{C}_{3} \mathrm{H}_{8}$ than the ones treated at $500{ }^{\circ} \mathrm{C}$. In contrast, the gas sorption behavior of the thermally treated membranes at lower temperatures $\left(<500{ }^{\circ} \mathrm{C}\right)$ follows the dual-mode sorption model (i.e., Henry and Langmuir modes). ${ }^{39}$ Their sorption concentrations exhibit convex curves against the pressure axis. This non-linear behavior is a typical sorption pattern of glassy polymeric membranes.

\subsection{Gas diffusivity and solubility}

Since the solubility coefficient can be calculated from $S=c / p$, Table 1 summarizes the corresponding solubility coefficients and diffusion coefficients at 3.5 atm and $35{ }^{\circ} \mathrm{C}$. For PIM, PIMCD-1\% and PIM-CD-2\%, the sharp drop of their permeability with an increase in the annealing temperature is mainly attributed to the decrease of the diffusion coefficient. The diffusion coefficient of $\mathrm{C}_{3} \mathrm{H}_{6}$ decreases about 100-fold from its original value of $6358 \times 10^{-10} \mathrm{~cm}^{2} \mathrm{~s}^{-1}$ in the pristine PIM to its minimum value of $59 \times 10^{-10} \mathrm{~cm}^{2} \mathrm{~s}^{-1}$ in the $600{ }^{\circ} \mathrm{C}$ treated membrane; meanwhile, the diffusion coefficient of $\mathrm{C}_{3} \mathrm{H}_{8}$ decreases about 200-fold from its original value of $2493 \times 10^{-10}$ $\mathrm{cm}^{2} \mathrm{~s}^{-1}$ to its minimum value of $11 \times 10^{-10} \mathrm{~cm}^{2} \mathrm{~s}^{-1}$. Fig. 13 plots the diffusion coefficient of all membranes as a function of annealing temperature. The diffusion coefficient has a slower decreasing speed with the annealing temperature for the membranes thermally treated up to $400{ }^{\circ} \mathrm{C}$ than those treated from 500 to $600{ }^{\circ} \mathrm{C}$, especially for PIM-CD membranes. This interesting characteristic is probably due to the fact that the bowl-shaped cavity of 3D $\beta$-CD can support the architecture and make the micro-pores unable to collapse when the thermal 

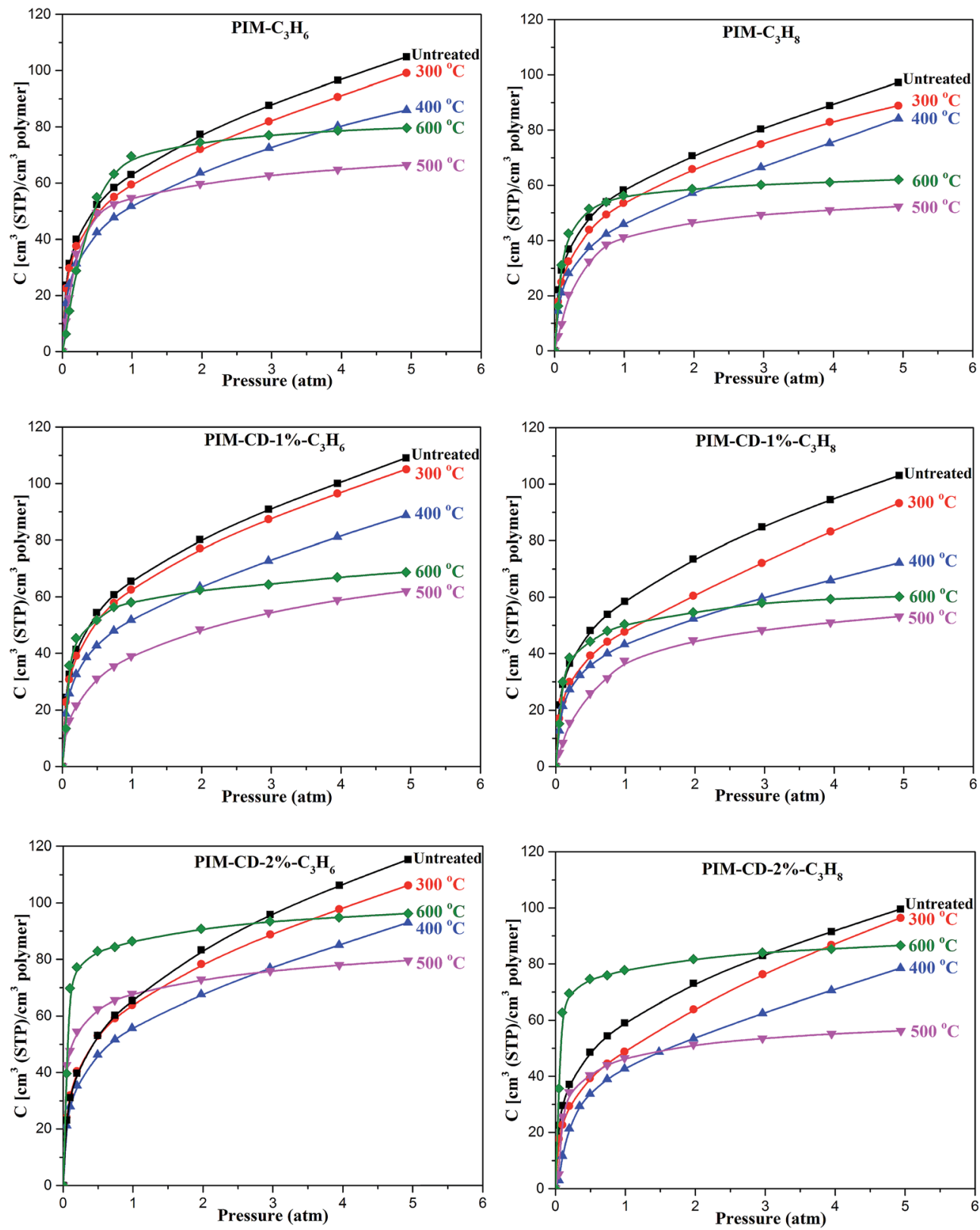

Fig. 12 Sorption isotherms of the untreated and thermally treated membranes at $35^{\circ} \mathrm{C}$.

treatment temperature is low. However, when the annealing temperature is higher than the glass transition temperature of PIM and the decomposition temperature of CD, the bowlshaped cavity of $3 \mathrm{D} \beta$-CD collapses. As a consequence, it densifies the polymer chains, shrinks the free volume and reduces the diffusion coefficients of the membranes treated at 500 or $600{ }^{\circ} \mathrm{C}$ significantly.

The diffusivity selectivity and solubility selectivity of the untreated and thermally treated membranes are shown in Fig. 14. Both the diffusivity selectivity and the solubility selectivity increase with increasing the thermal treatment temperature. The diffusivity selectivity increases faster than the solubility selectivity for all membranes. Since the ideal permeability selectivity can be defined as the product of diffusivity selectivity and solubility selectivity, the sharp increase of the gas permeability selectivity is mainly attributed to the increase of the diffusivity selectivity. The PIM-CD membranes after thermal treatment have a greater increase in the diffusivity selectivity than the PIM membrane. Comparing the diffusivity selectivity between the untreated and $600{ }^{\circ} \mathrm{C}$ treated PIM membranes, it increases from 2.5 to 5.4 with an increase of 2.2 times, while it increases from 2.3 to 6.1 with an increase of 2.7 times for the untreated and $600{ }^{\circ} \mathrm{C}$ treated PIM-CD-1\% membranes. Similarly, it increases from 2.3 to 6.6 with an increase of 2.9 times for the untreated and $600{ }^{\circ} \mathrm{C}$ treated PIM-CD-2\% membranes. Since the diffusivity selectivity essentially matches the actual pure-gas permselectivity for the whole temperature range, the molecular sieving mechanism is dominant in these thermally self-crosslinked membranes. 

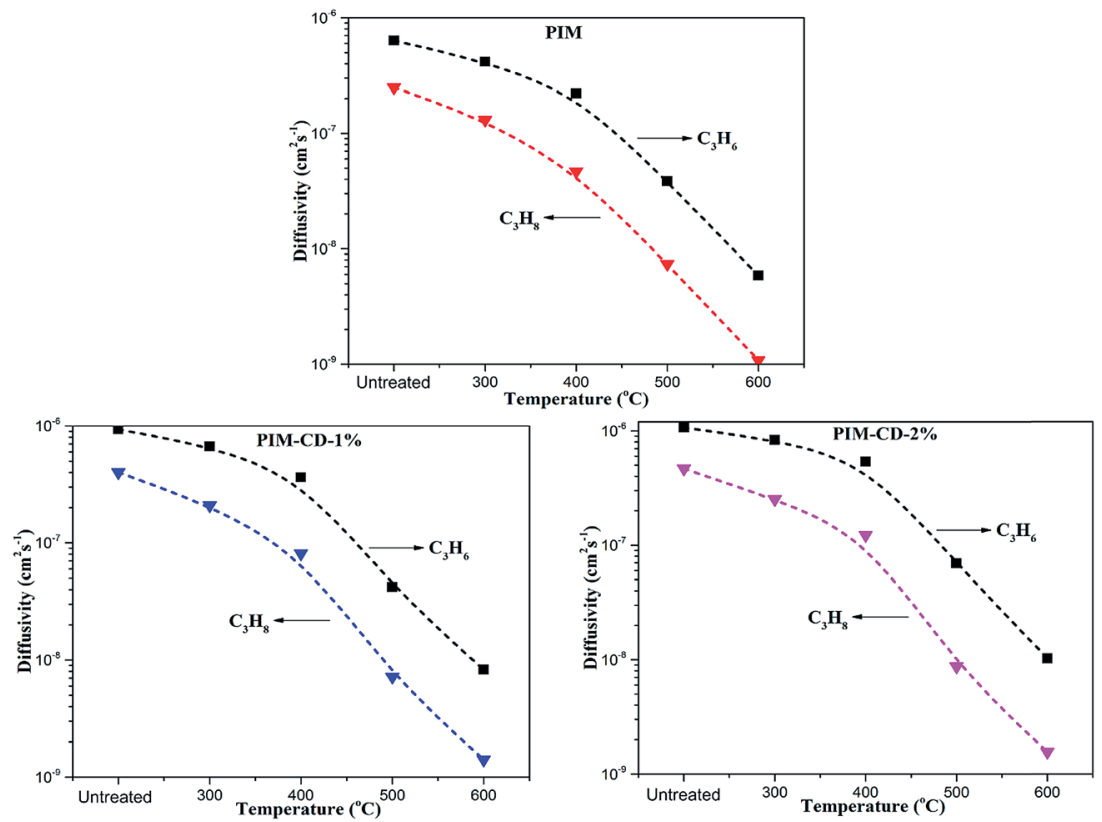

Fig. 13 The $\mathrm{C}_{3} \mathrm{H}_{6}$ and $\mathrm{C}_{3} \mathrm{H}_{8}$ diffusivity at 3.5 atm and $35^{\circ} \mathrm{C}$ (lines are drawn to guide the eyes).
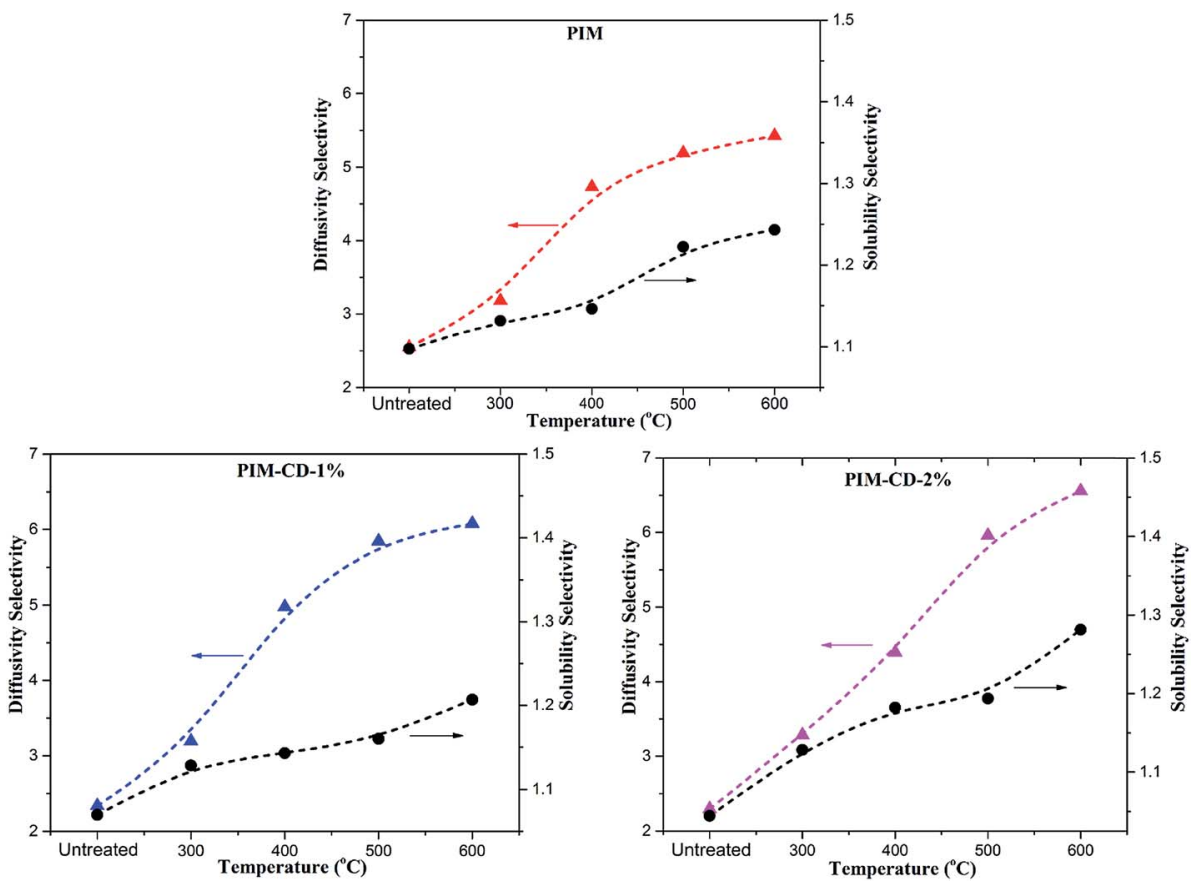

Fig. 14 The $\mathrm{C}_{3} \mathrm{H}_{6} / \mathrm{C}_{3} \mathrm{H}_{8}$ diffusivity and solubility selectivity at $3.5 \mathrm{~atm}$ and $35^{\circ} \mathrm{C}$ (lines are drawn to guide the eyes).

\section{Conclusions}

A series of PIM-CD polymers were prepared by incorporating thermally labile 3D $\beta$-CD into PIM polymer chains via chemical bonds from nucleophilic substitution copolymerization of $\beta-C D$, TFTPN, and TTSBI. Once the PIM-CD membranes are thermally treated at high temperatures, the thermal liable $\beta$-CD decomposes to generate free radicals, which can effectively accelerate the selfcross-linking reaction of nitrile. The formation of triazine rings tends to pull the PIM polymer chains approaching one another closely. Since the spaces originally occupied by CD convert to micro-pores while the rigidly contorted PIM polymer framework persists, the resultant 3D cross-linking networks have narrow gates for remarkably better size and shape selectivity while the overall permeability is still maintained sufficiently high for rapid gas diffusion. As a result, the selectivity for $\mathrm{C}_{3} \mathrm{H}_{6} / \mathrm{C}_{3} \mathrm{H}_{8}$ rises rapidly while the permeability just drops slightly. In addition to showing high mechanical flexibility, the PIM-CD membranes 
treated at 300 or $400{ }^{\circ} \mathrm{C}$ have separation performance surpassing the upper bound line in both pure and mixed gas tests.

\section{Acknowledgements}

The authors would like to thank the National University of Singapore (NUS) under the project entitled "Membrane research for $\mathrm{CO}_{2}$ capture" (Grant number: R-279-000-404-133), and the Dean's Office, Faculty of Engineering, NUS under the project title of Natural Gas Center (NUS grant number R-261-508-001-646) for funding this research. The authors also thank Dr Kuo-Sung Liao, Susilo Japip and Wai Fen Yong for their valuable assistance and fruitful discussion on search processes.

\section{References}

1 D. F. Sanders, Z. P. Smith, R. Guo, L. M. Robeson, J. E. McGrath, D. R. Paul and B. D. Freeman, Energyefficient polymeric gas separation membranes for a sustainable future: a review, Polymer, 2013, 54, 4729-4761.

2 R. B. Eldridge, Olefin/paraffin separation technology: a review, Ind. Eng. Chem. Res., 1993, 32, 2208-2212.

3 R. L. Burns and W. J. Koros, Defining the challenges for $\mathrm{C}_{3} \mathrm{H}_{6} / \mathrm{C}_{3} \mathrm{H}_{8}$ separation using polymeric membranes, $J$. Membr. Sci., 2003, 211, 299-309.

4 L. Liu, A. Chakma and X. Feng, Propylene separation from nitrogen by poly(ether block amide) composite membranes, J. Membr. Sci., 2006, 279, 645-654.

5 S. W. Kang, K. Char and Y. S. Kang, Novel application of partially positively charged silver nanoparticles for facilitated transport in olefin/paraffin separation membranes, Chem. Mater., 2008, 20, 1308-1311.

6 M. D. Guiver and Y. M. Lee, Polymer rigidity improves microporous membranes, Science, 2013, 339, 284-285.

7 N. Peng, N. Widjojo, P. Sukitpaneenit, M. M. Teoh, G. G. Lipscomb, T. S. Chung and J. Y. Lai, Evolution of polymeric hollow fibers as sustainable technologies: past, present, and future, Prog. Polym. Sci., 2012, 37, 1401-1424.

8 C. Zhang, Y. Dai, J. R. Johnson, O. Karvan and W. J. Koros, High performance ZIF-/6FDA-DAM mixed matrix membrane for propylene/propane separations, J. Membr. Sci., 2012, 389, 34-42.

9 S. S. Chan, R. Wang, T. S. Chung and Y. Liu, $\mathrm{C}_{2}$ and $\mathrm{C}_{3}$ hydrocarbon separations in poly(1,5-naphthalene-2,2' bis(3,4-phthalic)hexafluoropropane)diimide (6FDA-1,5NDA) dense membranes, J. Membr. Sci., 2002, 210, 55-64.

10 R. W. Baker, Future directions of membrane gas separation technology, Ind. Eng. Chem. Res., 2002, 41, 1393-1411.

11 R. J. Swaidan, B. Ghanem, R. Swaidan, E. Litwiller and I. Pinnau, Pure- and mixed-gas propylene/propane permeation properties of spiro- and triptycene-based microporous polyimides, J. Membr. Sci., 2015, 492, 116-122.

12 Z. P. Smith, G. Hernandez, K. L. Gleason, A. Anand, C. M. Doherty, K. Konstas, C. Alvarez, A. J. Hill, A. E. Lozano, D. R. Paul and B. D. Freeman, Effect of polymer structure on gas transport properties of selected aromatic polyimides, polyamides and TR polymers, J. Membr. Sci., 2015, 493, 766-781.
13 D. Liu, X. Ma, H. Xi and Y. S. Lin, Gas transport properties and propylene/propane separation characteristics of ZIF-8 membranes, J. Membr. Sci., 2014, 451, 85-93.

14 R. Faiz and K. Li, Polymeric membranes for light olefin/ paraffin separation, Desalination, 2012, 287, 82-97.

$15 \mathrm{R}$. Faiz and K. Li, Olefin/paraffin separation using membrane based facilitated transport/chemical absorption techniques, Chem. Eng. Sci., 2012, 73, 261-284.

16 T. C. Merkel, R. Blanc, I. Ciobanu, B. Firat, A. Suwarlim and J. Zeid, Silver salt facilitated transport membranes for olefin/ paraffin separations: carrier instability and a novel regeneration method, J. Membr. Sci., 2013, 447, 177-189.

17 R. S. Murali, K. Y. Rani, T. Sankarshana, A. F. Ismail and S. Sridhar, Separation of binary mixtures of propylene and propane by facilitated transport through silver incorporated poly(ether-block-amide) membranes, Oil Gas Sci. Technol., 2015, 70, 381-390.

18 L. Liu, X. Feng and A. Chakma, Unusual behavior of poly(ethylene oxide) $/ \mathrm{AgBF}_{4}$ polymer electrolyte membranes for olefin-paraffin separation, Sep. Purif. Technol., 2004, 38, 255-263.

19 S. Hess, C. Staudt-Bickel and R. N. Lichtenthaler, Propene/ propane separation with copolyimide membranes containing silver ions, J. Membr. Sci., 2006, 275, 52-60.

20 S. W. Kang, J. H. Kim, J. Won and Y. S. Kang, Suppression of silver ion reduction by $\mathrm{Al}\left(\mathrm{NO}_{3}\right)_{3}$ complex and its application to highly stabilized olefin transport membranes, J. Membr. Sci., 2013, 445, 156-159.

21 K. S. Liao, J. Y. Lai and T. S. Chung, Metal ion modified PIM1 and its application for propylene/propane separation, $J$. Membr. Sci., 2016, 515, 36-44.

22 I. Pinnau and L. G. Toy, Solid polymer electrolyte composite membranes for olefin/paraffin separation, J. Membr. Sci., 2001, 184, 39-48.

23 C. Zhang, Y. Dai, J. R. Johnson, O. Karvan and W. J. Koros, High performance ZIF-8/6FDA-DAM mixed matrix membrane for propylene/propane separations, J. Membr. Sci., 2012, 389, 34-42.

24 J. Ploegmakers, S. Japip and K. Nijmeijer, Mixed matrix membranes containing MOFs for ethylene/ethane separation part A: membrane preparation and characterization, J. Membr. Sci., 2013, 428, 445-453.

25 M. Askari and T. S. Chung, Natural gas purification and olefin/paraffin separation using thermal cross-linkable copolyimide/ZIF-8 mixed matrix membranes, J. Membr. Sci., 2013, 444, 173-183.

26 S. Japip, H. Wang, Y. C. Xiao and T. S. Chung, Highly permeable zeolitic imidazolate framework (ZIF-71) nanoparticles enhanced polyimide membranes for gas separation, J. Membr. Sci., 2014, 467, 162-174.

27 N. Hara, M. Yoshimune, H. Negishi, K. Haraya, S. Hara and T. Yamaguchi, Diffusive separation of propylene/propane with ZIF-8 membranes, J. Membr. Sci., 2014, 450, 215-223.

28 M. L. Chng, Y. C. Xiao, T. S. Chung, M. Toriida and S. Tamai, Enhanced $\mathrm{C}_{3} \mathrm{H}_{6} / \mathrm{C}_{3} \mathrm{H}_{8}$ separation by an ingenious carbonaceous membrane derived from PAEK/azide interpenetrating network, Carbon, 2009, 47, 1857-1866. 
29 X. Ma, Y. S. Lin, X. Wei and J. Kniep, Ultrathin carbon molecular sieve membrane for propylene/propane separation, AIChE J., 2016, 62, 491-499.

30 K. M. Steel and W. J. Koros, An investigation of the effects of pyrolysis parameters on gas separation properties of carbon materials, Carbon, 2005, 43, 1843-1856.

31 K. Okamoto, S. Kawamura, M. Yoshino, H. Kita, Y. Hirayama, N. Tanihara and Y. Kusuki, Olefin/paraffin separation through carbonized membranes derived from an asymmetric polyimide hollow fiber membrane, Ind. Eng. Chem. Res., 1999, 38, 4424-4432.

32 J. Hayashi, H. Mizuta, M. Yamamoto, K. Kusakabe, S. Morooka and S. H. Suh, Separation of ethane/ethylene and propane/propylene systems with a carbonized BPDApp'ODA polyimide membrane, Ind. Eng. Chem. Res., 1996, 35, 4176-4181.

33 X. L. Ma, B. K. Lin, X. T. Wei, J. Kniep and Y. S. Lin, Gammaalumina supported carbon molecular sieve membrane for propylene/propane separation, Ind. Eng. Chem. Res., 2013, 52, 4297-4305.

34 O. Salinas, X. H. Ma, E. Litwiller and I. Pinnau, Ethylene/ ethane permeation, diffusion and gas sorption properties of carbon molecular sieve membranes derived from the prototype ladder polymer of intrinsic microporosity (PIM1), J. Membr. Sci., 2016, 504, 133-140.

35 O. Salinas, X. H. Ma, E. Litwiller and I. Pinnau, Highperformance carbon molecular sieve membranes for ethylene/ethane separation derived from an intrinsically microporous polyimide, J. Membr. Sci., 2016, 500, 115-123.

36 P. M. Budd, B. S. Ghanem, S. Makhseed, N. B. McKeown, K. J. Msayib and C. E. Tattershall, Polymers of intrinsic microporosity (PIMs): robust, solution processable, organic nanoporous materials, Chem. Commun., 2004, 230-231.

37 P. M. Budd, E. S. Elabas, B. S. Ghanem, S. Makhseed, N. B. McKeown, K. J. Msayib, C. E. Tattershall and D. Wang, Solution-processed, organophilic membrane derived from a polymer of intrinsic microporosity, $A d v$. Mater., 2004, 16, 456-459.

38 F. Y. Li, Y. C. Xiao, T. S. Chung and S. Kawi, Highperformance thermally self-cross-linked polymer of intrinsic microporosity (PIM-1) membranes for energy development, Macromolecules, 2012, 45, 1427-1437.

39 P. Li, T. S. Chung and D. R. Paul, Gas sorption and permeation in PIM-1, J. Membr. Sci., 2013, 432, 50-57.

40 N. Y. Du, M. M. Dal-Cin, I. Pinnau, A. Nicalek, G. P. Robertson and M. D. Guiver, Azide-based cross-linking of polymers of intrinsic microporosity (PIMs) for condensable gas separation, Macromol. Rapid Commun., 2011, 32, 631-636.
41 J. T. Liu, Y. C. Xiao, K. S. Liao and T. S. Chung, Highly permeable and aging resistant 3D architecture from polymers of intrinsic microporosity incorporated with betacyclodextrin, J. Membr. Sci., 2017, 523, 92-102.

42 A. Alsbaiee, B. J. Smith, L. Xiao, Y. Ling, D. E. Helbling and W. R. Dichtel, Rapid removal of organic micropollutants from water by a porous $\beta$-cyclodextrin polymer, Nature, 2016, 529, 190-194.

43 K. Tanaka, A. Taguchi, J. Q. Hao, H. Kita and K. Okamoto, Permeation and separation properties of polyimide membranes to olefins and paraffins, J. Membr. Sci., 1996, 121, 197-207.

44 S. Bai, S. Sridhar and A. A. Khan, Metal-ion mediated separation of propylene from propane using PPO membranes, J. Membr. Sci., 1998, 147, 131-139.

$45 \mathrm{~S}$. Sridhar and A. A. Khan, Simulation studies for the separation of propylene and propane by ethylcellulose membrane, J. Membr. Sci., 1999, 159, 209-219.

46 P. S. Tin, T. S. Chung, Y. Liu, R. Wang, S. L. Liu and K. P. Pramoda, Effects of cross-linking modification on gas separation performance of Matrimid membranes, $J$. Membr. Sci., 2003, 225, 77-90.

47 Y. C. Xiao and T. S. Chung, Grafting thermally labile molecules on cross-linkable polyimide to design membrane materials for natural gas purification and $\mathrm{CO}_{2}$ capture, Energy Environ. Sci., 2011, 4, 201-208.

48 M. Askari, M. L. Chua and T. S. Chung, Natural gas purification and olefin/paraffin separation using crosslinkable, 6FDA-Durene/DABA co-polyimides grafted with $\alpha$, $\beta$, and $\gamma$-cyclodextrin, J. Membr. Sci., 2012, 390-391, 141-151.

49 M. Askari, T. X. Yang and T. S. Chung, Natural gas purification and olefin/paraffin separation using crosslinkable dual-layer hollow fiber membranes comprising $\beta$ cyclodextrin, J. Membr. Sci., 2012, 423-424, 392-403.

50 F. Y. Li, Y. C. Xiao, Y. K. Ong and T. S. Chung, UV-rearranged PIM-1 polymeric membranes for advanced hydrogen purification and production, Adv. Energy Mater., 2012, 2, 1456-1466.

51 M. M. Khan, G. Bengtson, S. Shishatskiy, B. N. Gacal, M. M. Rahman, S. Neumann, V. Filiz and V. Abetz, Crosslinking of Polymer of Intrinsic Microporosity (PIM-1) via nitrene reaction and its effect on gas transport property, Eur. Polym. J., 2013, 49, 4157-4166.

52 R. J. Swaidan, B. Ghanem, R. Swaidan, E. Litwiller and I. Pinnau, Pure- and mixed-gas propylene/propane permeation properties of spiro- and triptycene-based microporous polyimides, J. Membr. Sci., 2015, 492, 116-122. 